\title{
Hydrodesulfurization of Dibenzothiophene on a CoNiMo Catalyst
}

\begin{abstract}
RAMI DOUKEH ${ }^{1,2}$, TRAIAN JUGANARU ${ }^{1}$, ION BOLOCAN ${ }^{2 *}$
'Petroleum Gas University of Ploiesti, 39 Bucuresti Blvd., 100680, Ploiesti, Romania

${ }^{2}$ National Institute for Research Development for Chemistry and Petrochemistry- ICECHIM Bucuresti , 202 Splaiul Independetei, 060021, Bucharest, Romania

In order to evaluate the performance of $\mathrm{CoNiMo} / \mathrm{\gamma}-\mathrm{Al}_{2} \mathrm{O}_{3^{\prime}}$, the hydrogenolysis of dibenzothiophene was carried out. The conversion of dibenzothiophene, the yields of the reaction products and the unconverted sulfur content, expressed in ppm, were determined, at different temperatures in the catalytic layer $\left(300^{\circ} \mathrm{C}-360^{\circ} \mathrm{C}\right)$, pressures (40 bar-60 bar) and liquid hourly space velocity $\left(1-4 \mathrm{~h}^{-1}\right)$. The hydrodesulphurization catalyst was characterized by: determining the textural characteristics (BET specific surface area, mean pore diameter and pore volume), the acidic strength distribution, morphological analysis (scanning electron microscopy$S E M)$ and by identification of the species (X-ray diffraction - XRD). The analysis of the textural characteristics results in an ordered mesoporous structure of the catalyst, with a specific area of $280 \mathrm{~m}^{2} / \mathrm{g}$ and a medium pore diameter of $4.42 \mathrm{~nm}$. At high temperature of $360^{\circ} \mathrm{C}$ and pressure of $60 \mathrm{bar}$, the CoNiMo/ $\gamma-\mathrm{Al}_{2} \mathrm{O}_{3}$ exhibit a good activity in hydrodesulphurization with a $100 \%$ conversion of dibenzotiophene.
\end{abstract}

Keywords: hydrodesulphurization, dibenzothiophene, CoNiMo/y-Al $\mathrm{O}_{3}$ catalyst

In many countries, stricter regulations for fuels have been introduced, with the overall tendency to be cleaner and to contain compounds which can affect the environment (sulfur compounds, nitrogen and aromatic compounds), as few as possible and in very low concentrations. In European Union, the limit concentration for sulfur is $10 \mathrm{ppm}$, since J anuary 2009, when Euro5 type fuel has been introduced, compared to $500 \mathrm{ppm}$, the concentration allowed in 1996, for Euro 2 type fuels [1-3]. Petroleum fractions contain a complex mixture of sulfur compounds with different reactivity. In gasoline, are generally found mercaptans which have up to 8 carbon atoms in the molecule and acyclic and cyclic sulfides. In the middle distilates (oil and gasoline) are mainly found sulfides, thiophene and its derivates and bicyclic thioethers. Heavier petroleum fractions also contain bi- and polycyclic components with a thiophene or thiophene ring condensed with several aromatic or naphthenic cycles [4]. The type of compounds present, their reactivity, the reaction mechanism, the kinetics of hydrodesulfurization, and the factors that influence the reactivity of the sulfur compounds must be clearly know $n$ for the desulfurization process. The sulfur compounds most studied are thiols (mercaptans), thioethers (sulphides), disulfides, thiophene, benzothiophene and dibenzothiophene $[5,6]$. There are a lot of possibilities for hydrodesulfurization catalysts, and their choice in refineries usually adapts to the characteristics of the petroleum fractions and to the specifications of the refined product. The most used catalysts have the active component in the form of molybdenum sulfide or tungsten, to which cobalt and nickel are added as promoters. Other possibilities are Ni-Mo, Ni-W, or Co-W rarely [7]. $\gamma$-Alumina, $\left(\gamma-\mathrm{Al}_{2} \mathrm{O}_{3}\right)$ is the most commonly used support for the preparation of hydrodesulfurization catalysts [8] . $\gamma$-Alumina crystallizes in cubic form with structural defect in which the oxygen atoms are arranged in a compact cube network and the aluminum atoms are arranged in a tetrahedral and octahedral network. In order to achieve $\gamma-\mathrm{Al}_{2} \mathrm{O}_{3}$ stoichiometry, starting from the chemical formula of a M304 spinel (M-metal or metal combinations), the positions for the Al atoms are not fully occupied. Vacant positions are distributed both on octahedral and tetrahedric centers. The distribution of $\mathrm{Al}$ atoms is dependent on the synthesis method [9-10]. Zhang et al. [11] used the sol-gel method for $\gamma-\mathrm{Al}_{2} \mathrm{O}_{3}$ support, in order to obtain NiMo catalysts for diesel hydrodesulphurisation. They used an inorganic precursor, $\mathrm{AlCl}_{3} \cdot 6 \mathrm{H}_{2} \mathrm{O}$ or Al $\left(\mathrm{NO}_{3}\right)_{3} \cdot 6 \mathrm{H}_{2} \mathrm{O}$ as the source of aluminum, polyethylene glycol (PEG 400) and $\mathrm{NH}_{3} \cdot \mathrm{H}_{2} \mathrm{O}$. Also by gel-based gel, butstarting from an organic precursor, Araiza et al. synthesized $\gamma-\mathrm{Al}_{2} \mathrm{O}_{3}$ and for the Pt, Pd catalyst for the hydrodesulfurization studies of 4,6-dimethyldibenzothiophene [12]. Several metals demonstrated to be active in the hydrodesulfurization process, with numerous studies on transition metal sulfides $[13,14]$. The activities of metal sulphides (supported or not), for the hydrodesulphurization of thiophene $[15,16]$ and benzothiophene [17] depend on the position of the metal in the periodic system. Even though there are small differences between studies, all show that transition metals in the second and third groups have a volcano-type dependence between activity and position in the periodic system, and are generally more active than those in the first column, le Ru, Os, Rh, Ir [18], MoS 2 beeing the most widely used industrial catalyst.

\section{Experimental part}

Catalyst preparation and characterization

The CoNiMo $/ \gamma-\mathrm{Al}_{2} \mathrm{O}_{3}$ catalyst was prepared by the incipient wetness co-impregnation using ammonium molybdate tetrahydrate, cobalt (II) nitrate hexahydrate (Sigma-Aldrich) and nickel (II) nitrate hexahydrate respectively [19]. After each impregnation step, the catalyst was dried for $24 \mathrm{~h}$ and calcined for $4 \mathrm{~h}$ at $450{ }^{\circ} \mathrm{C}$, with the exception of the final calcination that last $6 \mathrm{~h}$.

After the final calcination step, the catalyst was activated in a hydrogen stream at $450^{\circ} \mathrm{C}$ for $4 \mathrm{~h}$. The composition of the active phase of the prepared catalyst was: $11.5 \%$ Mo, $3 \% \mathrm{Co}$ and $2 \% \mathrm{Ni}$.

Textural characteristics: surface area, pore volume, average pore diameter and pore-size-distribution were determined on a Autosorb 1 Quantacrome. The specific surface area (SSA) was calculated using the BrunauerEmmett-Teller (BET) method for relative pressure $\left(p / p_{0}\right)$ ranged between 0 and 1 . Pore volume $(V p)$ were 
determined by nitrogen adsorption at a relative pressure of 0.99 and pore size distributions from the branch isotherms adsorption by Barrett-J oyner-Halenda $(\mathrm{BJ} H)$ method were also taken into account. The acid strength distribution of the active center has been determined by the method of thermal desorption of diethyl-amine on a DuPont Instruments Thermal Analyst 2000/2100 coupled with a module 951 Thermogravimetric Analizer. XRD measurements were carried outwith a Bruker D8Advance $X$-ray equipment using CuK $\alpha$ radiation. SEM images were collected using a FEl Inspect, S model microscope.

The physicochemical properties of catalyst are characterized and correlated with the observed hydrodesulfurization activities of dibenzothiophene.

\section{Dibenzothiophene hydrodesulphurisation tests}

Hydrodesulphurization of dibenzothiophene was performed in a high-pressure fixed-bed continuous reactor at pressures $(p)$ ranging from 40 bar to 60 bar, temperatures (T) of 300 to $360^{\circ} \mathrm{C}$ and liquid hourly space velocity (LHSV) from $2 h^{-1}$ to $4 h^{-1}$. The feed consisted of a solution of $1.73 \%$ wt of dibenzothiophene (Aldrich, 99\%) in hexane (SigmaAldrich, 99\%). Prior to the activity test, the catalyst was sulfided using a $1 \%$ dimethyldisulphide solution (in hexan) at $350^{\circ} \mathrm{C}$ and 5 bar. The samples were collected and analyzed by gas chromatography equipped with mass spectrometer CP-3800 Triple Quad Agilent Techologies, on a DB-5 column.

\section{Results and discutions}

\section{Catalyst characterization}

The nitrogen adsorption-desorption isotherms for the CoNiMo/ $\gamma-\mathrm{Al}_{2} \mathrm{O}_{3}$ catalyst and the pore size distribution are shown in Fig. 1 . The catalyst display a type IV isotherm according to IUPAC classification and a hysteresys loop characteristic to cylindrical pores [20]. The nitrogen, begins to condense in the pores of the catalyst, at relative pressures $\left(p / p_{0}\right)$ of 0.4 when the hysteresis loop appears, and at the relative pressure $\left(p / p_{0}\right)$ of 1 , the pores are completely filled with the condensed liquid. From the analysis of the textural data (Table 1 and Figure 1), it is observed that the catalyst has a uniform pore size distribution, with an mean diameter

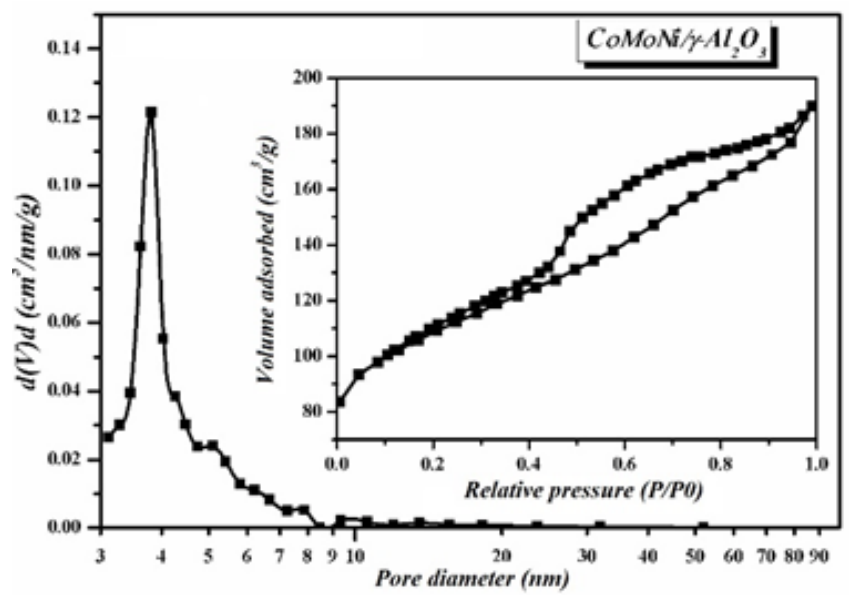

Fig. 1. Pore size distributions and adsorption desorption isotherm of the catalyst

Tabel 1

TEXTURAL PROPERTIES OF THE CATALYST

\begin{tabular}{|c|c|c|}
\hline $\begin{array}{c}\text { Specific } \\
\text { are } \mathbf{B E T} \\
\left(\mathbf{m}^{2} / \mathbf{g}\right)\end{array}$ & $\begin{array}{c}\text { Pore } \\
\text { volume } \\
\left(\mathbf{c m}^{3} / \mathbf{g}\right)\end{array}$ & $\begin{array}{c}\text { The mean pore } \\
\text { diameter }(\mathbf{n m})\end{array}$ \\
\hline 163.4 & 0.18 & 4.2 \\
\hline
\end{tabular}

of $4.2 \mathrm{~nm}$, a total pore volume of $0.18 \mathrm{~cm}^{3} / \mathrm{g}$ and a surface specific surface area of $163.4 \mathrm{~m}^{2} / \mathrm{g}$.

Diethylamine thermodesorption curve of the catalyst is shown in Figure 2. $\left(160-300^{\circ} \mathrm{C}\right.$-concentration of weak acidic centers, $300^{\circ} \mathrm{C}-440^{\circ} \mathrm{C}$-concentration of centers with medium acidity, $450-580^{\circ} \mathrm{C}$-concentration of centers with high acidity) [21]. On the basis of the thermodesorption curve of the catalyst, it was calculated the stength of acid sites and total acidity (Table 2). The total acidity of the CoNiMo/ $\gamma-\mathrm{Al}_{2} \mathrm{O}_{3}$ catalyst is $0.621 \mathrm{meq} / \mathrm{g}$ with $0.33 \mathrm{meg} / \mathrm{g}$ representing the concentration of weak acid sites. The concentration of medium acid sites is $0.165 \mathrm{meq} / \mathrm{g}$ and the concentration of strong acidic sites is $0.126 \mathrm{meq} / \mathrm{g}$ catalyst. From the analysis of the acid strength distribution, the catalyst has a low acidity.

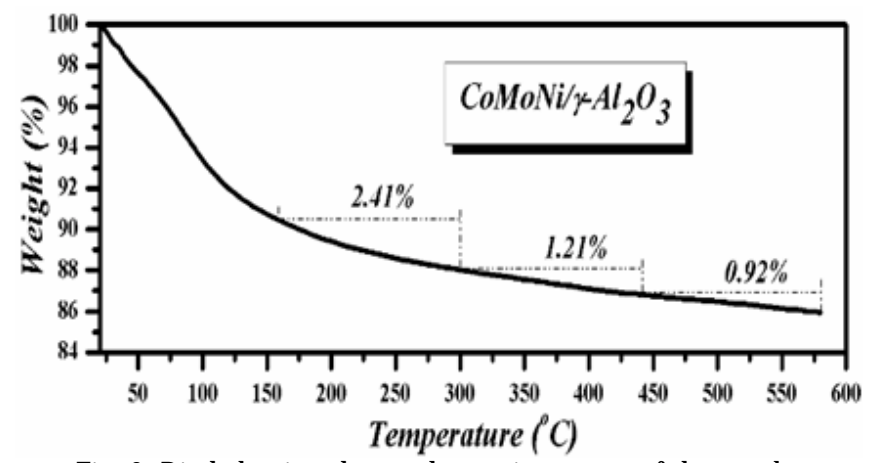

Fig. 2. Diethylamine thermodesorption curve of the catalyst

Table 2

ACID STRENGTH DISTRIBUTION OF THE CATALYST

\begin{tabular}{|l|c|}
\hline Acidic center type & $\begin{array}{c}\text { Concentration } \\
\text { (miliechivalenți/g) }\end{array}$ \\
\hline Weak & 0.330 \\
\hline Medium & 0.165 \\
\hline Strong & 0.126 \\
\hline $\begin{array}{l}\text { TOTAL } \\
\text { concentration }\end{array}$ & 0.621 \\
\hline
\end{tabular}

The XRD diffractogram (Figure 3) show the characteristic peaks of alumina and MoCo confirming the presence of CoMoOx, the crystalline molybdenum oxide and nichel oxide. The $X$-Ray pattern shows peaks at 2theta $=36.7^{\circ} ; 45.5^{\circ}$ and $66.8^{\circ}$ which are related to crystal phase of $\gamma-\mathrm{Al}_{2} \mathrm{O}_{3}[22-23]$. As depicted in the SEM images (Figure 4), the active phases were well distributed on the alumina surface.

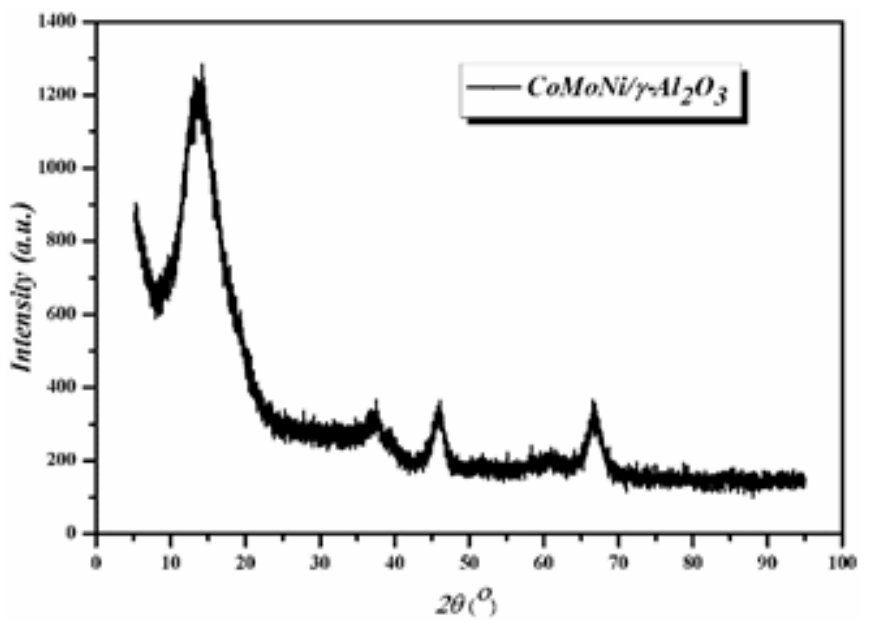

Fig. 3. XRD pattern of the catalyst 


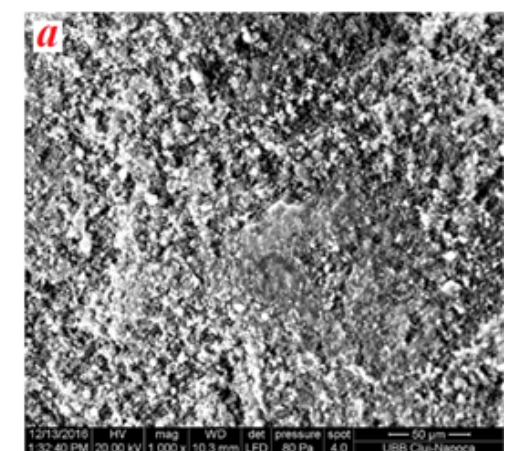

Fig.4. SEM images of the catalyst

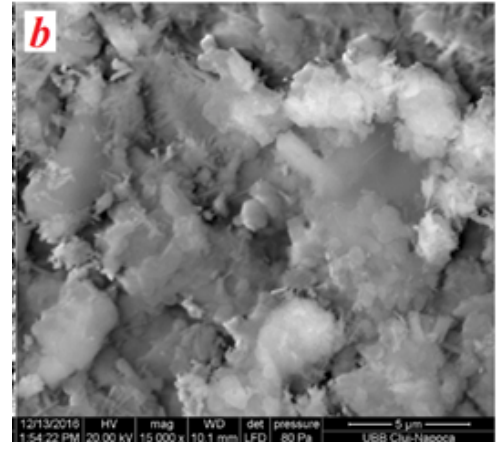

Hydrodesulphurization tests

From the GC-MS analysis of the reaction products there were mainly identified biphenyl, phenylciclohexane and biciclohexil.

\section{Effect of reaction temperature}

The dibenzothiophene conversion values and sulphur contents achived at 30 bar and LHSV of $1^{-1}$, at different temperatures, are shown in Figure 5. It is clear the beneficial effect of temperature on the catalyst activity. At $300^{\circ} \mathrm{C}$ the benzothiophene conversion was $55.07 \%$ and achieved $96.16 \%$ at $360^{\circ} \mathrm{C}$. The initial sulphur content in the feed was 3000 ppm and deacreased after hydrodesulphurization process to $1347 \mathrm{ppm}$ at $300^{\circ} \mathrm{C}$ and to 115 ppm at $360^{\circ} \mathrm{C}$.

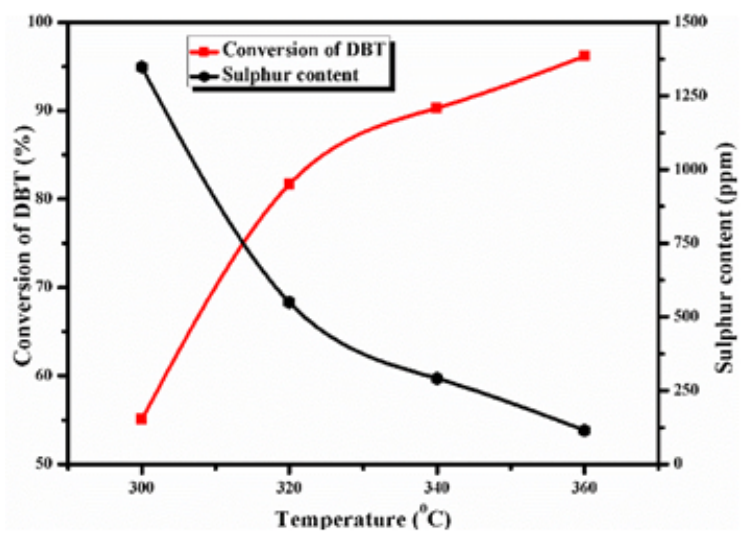

Fig.5. Influence of temperature on dibenzothiophene conversion and sulphur content, at 30 bar and LHSV $1 h^{-1}$

The yields in the reaction products, at temperature from 300 to $360^{\circ} \mathrm{C}$, pressure of 30 bar and LHSV of $1 h^{-1}$ are shown in Figure 6. The yield in biphenyl was $47.62 \%$ at $300^{\circ} \mathrm{C}$ and continuously increased to $69.16 \%$ at $360^{\circ} \mathrm{C}$. The yield in phenylciclohexane also increased with temperature from 6.14 to $19.87 \%$.

\section{Effect of pressure}

Increasing the pressure from 30 bar to 60 bar, at constant temperature of $360^{\circ} \mathrm{C}$ and LHSV of $1 \mathrm{~h}^{-1}$, the activity of the prepared catalyst CoNiMo $/ \gamma-\mathrm{Al}_{2} \mathrm{O}_{3}$, on dibenzothiophene hydrodesuphurization was improved. The conversion

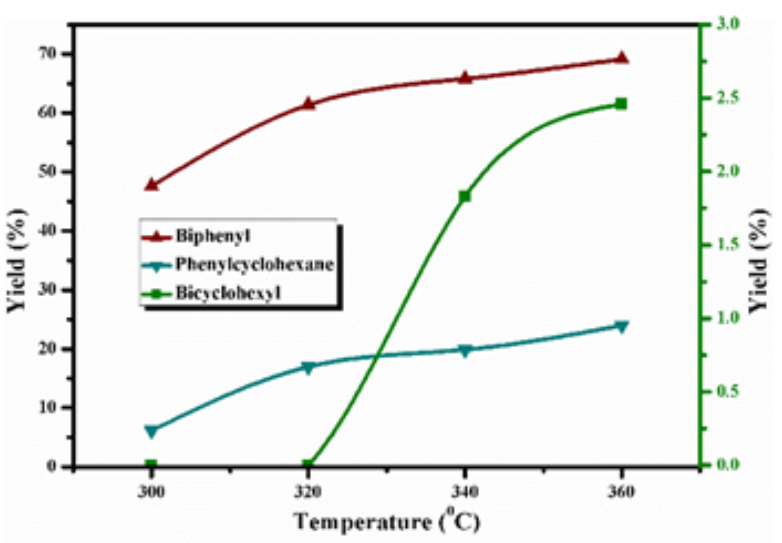

Fig. 6. Influence of temperature on the reaction products yields, at 30 bar and LHSV $1 h^{-1}$

increased from $96.16 \%$ at 30 bar to $100 \%$ at 60 bar and the sulphur content was reduced to zero at 60 bar (Figure 7). An increased pressure favors the formation of phenylciclohexan and biciclohexil, while the yield in biphenyl deacreased from $69.15 \%$ to $38.46 \%$, for pressures from 30 bar to 60 bar (Figure 8).

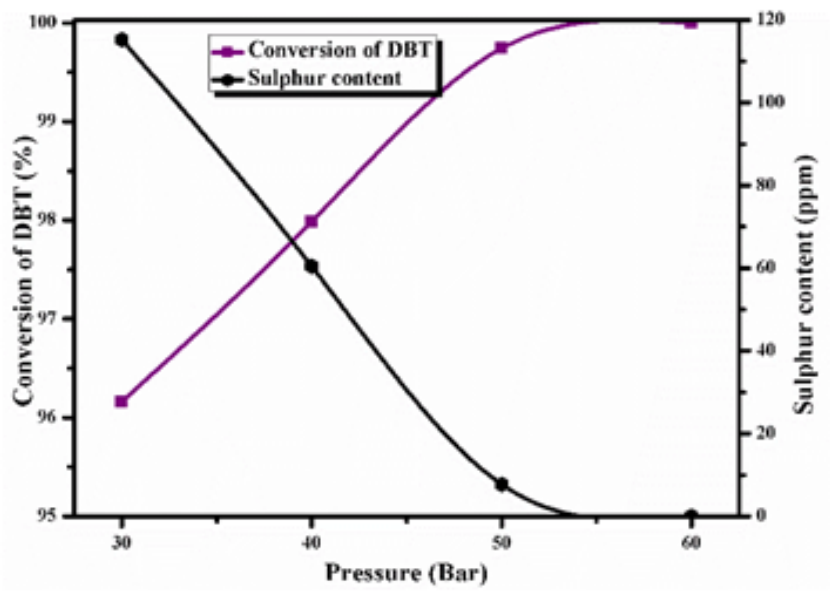

Fig. 7. Influence of pressure on dibenzothiophene conversion and sulphur content, at $360^{\circ} \mathrm{C}$ and LHSV $1 h^{-1}$

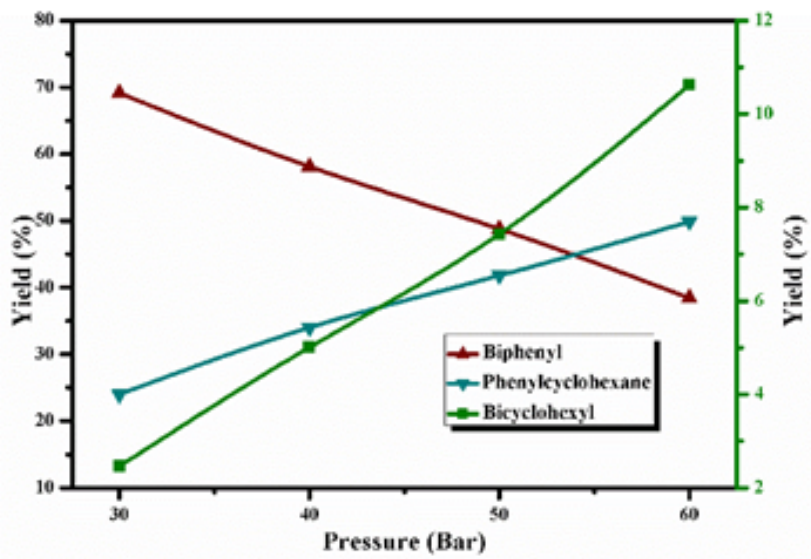

Fig. 8. Influence of pressure on the reaction products yields, at $360^{\circ} \mathrm{C}$ and LHSV $\mathrm{hh}^{-1}$

\section{Effect of liquid hourly space velocity}

Figure 9 shows the variation of benzothiophene conversion and sulphur content with liquid hourly space velocity, at $360^{\circ} \mathrm{C}$ and a pressure of 60 bar. As expected, at higher LHSV, because of shorter contact time between raw material and catalyst, the conversion of benzothiophene decreased. The sulphur content at $4 \mathrm{~h}^{-1}$ was $376 \mathrm{ppm}$ and it was reduced to zero at $1 h^{-1}$. 


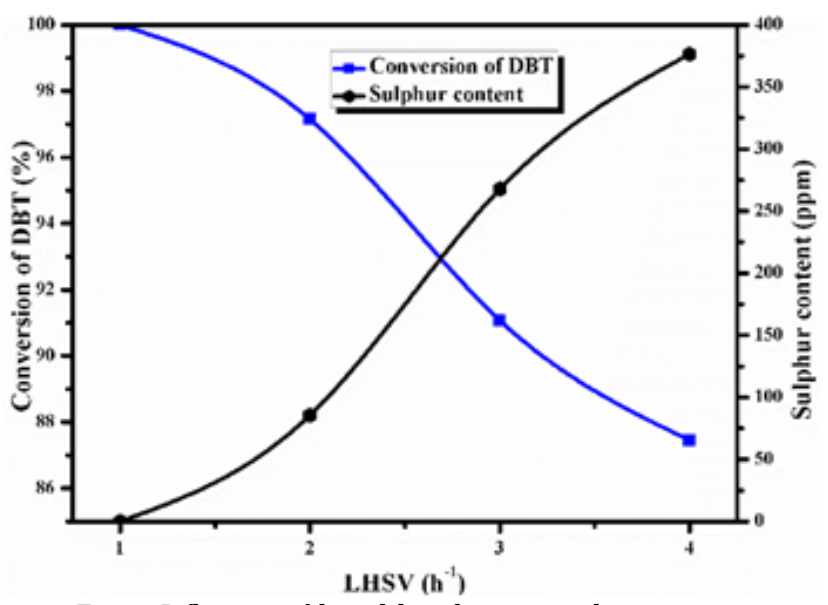

Fig. 9. Influence of liquid hourly space velocity on dibenzothiophene conversion and sulphur content, at $360^{\circ} \mathrm{C}$ and 60 bar

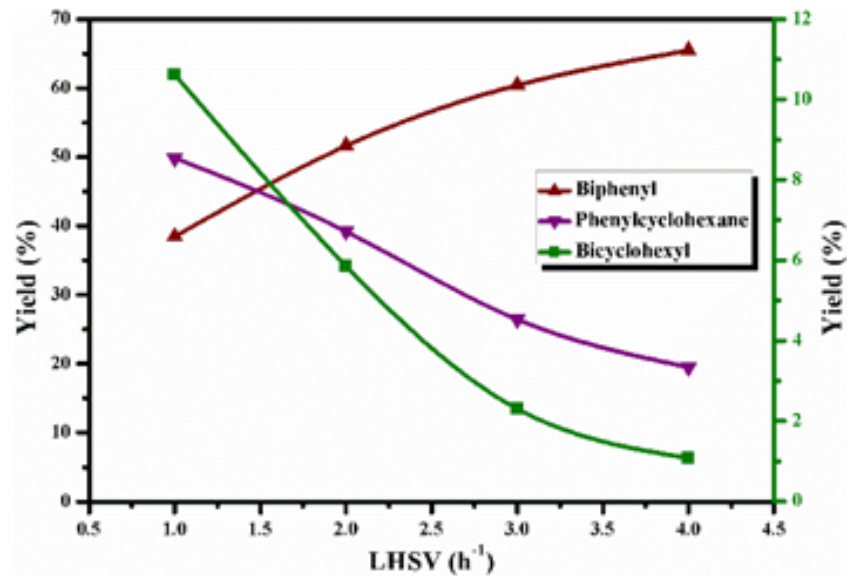

Fig. 10. Influence of liquid hourly space velocity on the reaction products yields, at $360^{\circ} \mathrm{C}$ and $60 \mathrm{bar}$

The formation of bicyclohexyl and phenylcyclohexane is negatively influenced by LHSV. The yield in bicyclohexyl decreased from $10.7 \%$ to $1 \%$ when LHSV increased from $1 h^{-1}$ to $4 h^{-1}$, and the yield in phenylcyclohexane decreased from 49.87 to $19.52 \%$.

\section{Conclusions}

The catalyst display a type IV isotherm according to IUPAC classification and a hysteresys loop characteristic to cylindrical pores.

The catalyst has a low acidity, the total acidity being $0.621 \mathrm{meg} / \mathrm{g}$ from which the concentration of weak acid sites was $0.33 \mathrm{meq} / \mathrm{g}$.

The XRD diffractogram show the characteristic peaks of alumina and MoCo confirming the presence of $\mathrm{CoMoOx}$, the crystalline molybdenum oxide and nichel oxide.

The reaction products there were biphenyl, phenylcyclohexane and bicyclohexyl.

The yield in phenylcyclohexane and bicyclohexane increases with temperature after a slower slope than the yield in biphenyl.
An increased pressure favors the formation of phenylcyclohexane and bicyclohexyl, while the yield in biphenyl deacreased.

The formation of bicyclohexyl and phenylcyclohexane is negatively influenced by LHSV.

\section{References}

1. KISS, E.F., MICIC, D.R., TOMIC, D.M., NIKOLI-DJ ORIC, B.N., SIMIKIC, D.M., The J ournal of Supercritical Fluids, 86, 2014, p. 23-32,.

2.*** https://ww w.sciencepolicycircle.org/55-sulphur-content-indiesel-a-review

3.*** DIRECTIVE 2009/30/EC OF THE EUROPEAN PARLIAMENT AND OF THE COUNCIL

4. SUCIU, C.G.,TUNESCU, C.T., Ingineria prelucrarii hidrocarburilor, vol. 1, Editura tehnica, Bucuresti, 1981.

5. RASEEV, S., Conversia hidrocarburilor, vol. 3, Editura Zecasin, Bucuresti, 1997.

6. SPEIGHT, J.G., The Chemistry and Technology of Petroleum, CRC Press Taylor \& Francis Group, 2014.

7. SANCHEZ-DELGADO, A.R., Organometallic Modeling of the Hydrodesulfurization and Hydrodenitrogenation Reactions, Kluwer Academic Publishers, New York, 2002.

8. ANCHEYTA, J., Modelling and Simulation of Catalytic Reactors for Petroleum Refining, John Wiley \& Sons, New Jersey, 2011.

9. SAMAIN, L., JAW ORSKI, A., EDEN, M., LADD, M.D., SEO, D.K., GARCIAGARCIA, F.J., HÄUSSERMANN, U., Journal of Solid State Chemistry, 217, p. 1-8, 2014.

10. ZHOU, R., SNYDE, R.I., Acta Crystallographica Section B, 47(5), p. 617-630, 1991.

11. ZHANG, M., FAN.J, CHI, K., DUAN. A., ZHAO, Z., MENG, X., ZHANG, H., Fuel Processing Technology, 156, p. 446-453, 2017.

12.CASTILLO-ARAIZA, C.O., CHIAVEZ, G., DUTTA, A., REYES, J.A., NUNEZ, S., GARCIA-MARTINEZ, J.C., Fuel Processing Technology, 132, p. 164-172, 2015.

13. TOPSOE, H., CLAUSEN, B.S., MASSOTH, F.E., Hydrotreating Catalysis Science and Technology, Springer-Verlag New York, 1996.

14.RAYBAUD, P., KRESSE, G., HAFNER, J., TOULHOAT, H., Journal of Physics: Condensed Matter, 9(50), p. 11085-11106, 1997.

15.VISSERS, J.P.R., GROOT, C.K., VAN OERS E.M., DE BEER V.H.J., PRINS, R., Bulletin des Societes Chimiques Belges, 93(8-9), p. 813$822,1984$.

16.LEDOUX, M.J., MICHAUX, O., AGOSTINI, G., Journal of Catalysis, 102(2), p. 275-288, 1986.

17.PECORARO, T.A., CHIANELLI, R. R., J ournal of Catalysis, 67(2), p. 430-445, 1981.

18.WEBER, T., PRINS, R., VAN SANTEN, R.A., Transition Metal Sulphides. Chemistry and Catalysis, Nato ASI, vol. 60, Springer Science+Business Media, Dordrecht, 1998.

19. DOUKEH, R., BOMBOS, M., POPOVICI, D., PASARE, M., BOLOCAN, I., Rev. Chim.(Bucharest), 70, no. 1, 2019, p.27.

20. UDREA, I., Elemente de catalizs eterogens 1995, Bucuresti: Editura Universitãii Bucuresti.

21. DOUKEH, R., BOMBOS, M., TRIFOI, A., PASARE, M., BANU, I., BOLOCAN, I., Rev.Chim. (Bucharest), 68, no. 7, 2017, p.1496.

22. ZHANG, M., FAN.J, CHI, K., DUAN. A., ZHAO, Z., MENG, X., ZHANG, H., Fuel Processing Technology, 156, p. 446-453, 2017.

23. DOUKEH, R., TRIFOI, A., BOMBOS, M., BANU, I., PASARE, M., BOLOCAN, I., Rev. Chim. (Bucharest), 69, no. 2, 2018, p.396 Hidrodesulfurarea dibenzotiofenului pe catalizator CoNiMo

Manuscript received: 17.04 .2019 